\title{
Comparative Study between Interlocking Nail and Locked Plate in Distal Tibial Fractures Fixation
}

\author{
Ahmed Mostafa Ibrahim ${ }^{1}$ MBBCh, Ismael Ahmed Yassin ${ }^{1}$ MD, and Ahmed Saied Mohammed ${ }^{1}$ MD
}

\section{*Corresponding Author: \\ Ahmed Mostafa Ibrahim \\ elmezian2262020@gmail.com}

\author{
Received for publication \\ December 28, 2020; Accepted \\ January 25, 2021; Published \\ online January 31, 2021.
}

Copyright 2020 The Authors published by Al-Azhar University, Faculty of Medicine, Cairo, Egypt. All rights reserved. This an openaccess article distributed under the legal terms, where it is permissible to download and share the work provided it is properly cited. The work cannot be changed in anyway or used commercially.

10.21608/aimj.2021.55564.1386

${ }^{1}$ Orthopedic Surgery Department, Faculty of Medicine, Al-Azhar University.

Disclosure: The authors have no financial interest to declare in relation to the content of this article. The Article Processing Charge was paid for by the authors.

Authorship: All authors have a substantial contribution to the article.

\begin{abstract}
Introduction: Distal tibial fractures accounts for approximately $37.8 \%$ of all tibial injuries affecting all ages. Treatment of distal tibial fractures in skeletally mature patients is challenging because of its unique anatomical characteristics of subcutaneous location with weak blood supply and proximity to the ankle joint. The aim of the study is to compare the results of fixation of extra-articular distal tibial fractures in adults by ILN vs. distal tibial locked plate with MIPPO.
\end{abstract}

Patients \& Methods: This study was done at Al-Azhar University Hospital, during the period of January 2020 to December 2020. 20 patients were recruited for this study to compare ILN vs distal tibial locked plate with MIPPO technique in fixation of extra-articular distal tibial fractures. Patients were assessed clinically using Olerud and Molander score and radiologically at 6 months.

Results: Age range of the patients was 20-57yr. Most common mode of trauma was RTA. Associated fibula fracture was present in 9 (90\%) of patients in both groups. Difference between 2 groups regarding demographic data, AO classification, operative time wasn't significant .No significant intraoperative complications were noted in both groups. The average time for union was 13.10 weeks (range, 1216 weeks) in group 1 and 16.78 weeks (range, 12-24 weeks), malunion was found in $20 \%$ of patients in group 1 and $10 \%$ of patients in group 2.

Conclusion: The overall results were comparable and most patients were satisfied with the results. These results indicate that both modalities of treatment deserve a place in treating distal Tibial fractures.

Keywords: Distal tibia fracture; MIPPO; ILN.

\section{INTRODUCTION}

Fracture is the result of mechanical overload with important biological consequences. Proper understanding of mechanical and biological aspects of fracture repair is the key for selection of particular type of treatment modality fora given fracture. ${ }^{1}$

Tibia is the most commonly broken long bone in the body. Injuries usually require hospital admission and frequently require surgery, resulting in prolonged periods (months) away from work and social activities. Tibial diaphysis is the most common site of fracture in the tibia and about $80 \%$ of these injuries have associated fibular fractures. ${ }^{2}$ Published data suggest an incidence of 17 per 100,000 personyears, although more recent data indicate that the incidence may be declining. ${ }^{3}$

Distal tibia shaft fractures account for approximately $37.8 \%$ of all tibial injuries. Fractures of the distal tibia affecting all ages. Treatment of distal tibial fractures in skeletally mature patients without 
distal tibia fractures, and good outcomes have been obtained.Intramedullary nailing (IMN) allows minimally invasive, symmetric, and dynamic fracture fixation following the principles of biological fracture fixation, and this technique also has been widely used for distal tibia shaft fractures with good results. Each of these techniques has their advantages and disadvantages. Non-operative treatment may be associated with joint stiffness in up to $40 \%$ of cases as well as shortening and rotational malunion in over $30 \%$ of cases. ${ }^{5}$

\section{PATIENTS AND METHODS}

From January 2020 to December 2020, a prospective randomized study was conducted at Al-Azhar University Hospital including 20 patients to compare ILN vs. distal tibial locked plate with MIPPO technique in fixation of extra-articular distal tibial fractures.

We included adults (aged more than 18 years) males and females with closed extraarticular metadiaphyseal fractures of the lower third of tibia. We excluded patients with open, intra articular fractures and those with neurovascular injury.

At enrollment, all patients were subjected to the following: Full history taking from patients including personal history, medical history, mode, time of trauma, pre-fracture level of activity. Complete clinical examination depending on ATLS protocol and local examination of the injured limb, Basal laboratory work-up: (CBC, PT PTT INR, AST ALT, Serum Creatinine Blood Urea and RBS) and Radiological Examination including Plain X-rays AP and Lat views of the affected leg andCT scan in cases where the involvement of articular surface is suspected.

Twenty patients who met the inclusion criteria were randomized by closed envelop technique to 2 groups; 10 patients in each group: Group A included patients fixed by ILN, and Group B included patients fixed by locked plate with MIPPO technique.

Twenty envelops were prepared: 10 for ILN and 10 for MIPPO. An envelope was opened before the surgery by an independent person, and the chosen technique was done.

\section{Operative procedures:}

Group A: Fixation by locking intramedullary nail: Patients were placed supine with the knee flexed 90 degree on a radiolucent table, deep skin incision was transpatellar, medial or even lateral parapatellar extending from the inferior pole of the patella to the tibial tuberosity. The entry point in A.P. view was in line with the axis of the intramedullary canal in lateral view the entry point was at the ventral edge of the tibial plateau. ${ }^{6}$ Fracture reduction is very important in intramedullary nailing, Insertion of the guide wire reaming was performed with deep fluted, small core diameter sharp reamers, then the nail inserted. Finally insertion of proximal and distal interlocking screws, Using expert nails provides multidirectional interlocking screws, the surgical wounds were closed in layers with interrupted absorbable sutures. The paratenon of the patellar tendon sheath is repaired if has been opened as part of the approach.
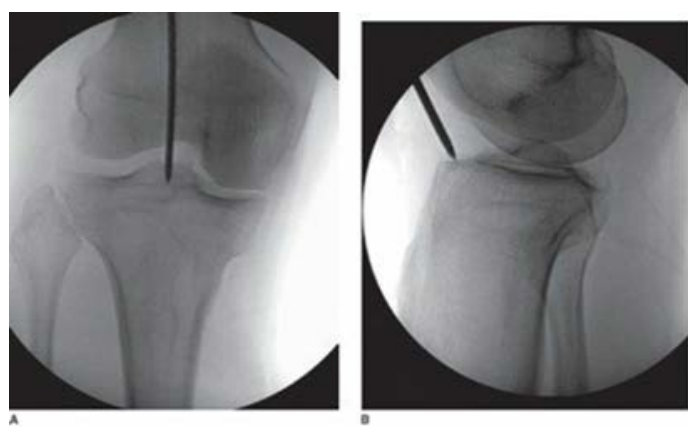

Fig.1: AP (A) and Lateral (B) views of the proximal tibia demonstrate the ideal starting point for a tibial nail. With either an awl or with a guide pin that can be enlarged with a cannulated drill or awl.

Group B: Distal tibial locked plate with MIPPO technique: Patients were positioned supine on a radiolucent operative table with elevation of the contralateral iliac crest. A $2-3 \mathrm{~cm}$ incision was made along the antero-medial aspect of the tibia distally at the level of the medial malleolus and proximally about 2-3 cm incision proximal to the end of fracture line. A subcutaneous extra periosteal tunnel was created using a Cobb dissector to introduce the plate. Percutaneous closed reduction of the fracture was done by manual manipulation, percutaneous clamps or fixator assisting reduction. The distal screws were then inserted, two screws were usually inserted one over the medial malleolus and one right below the fracture site, the later screw helps in bony reduction, taking advantage of the anatomical configuration of the plate. With preservation of reduction, proximal screws were taken through small incisions, then the remaining distal screws. (Fig. 2). Care must be taken during closure of subcutaneous tissue to cover the plate properly, and skin not to be under tension.

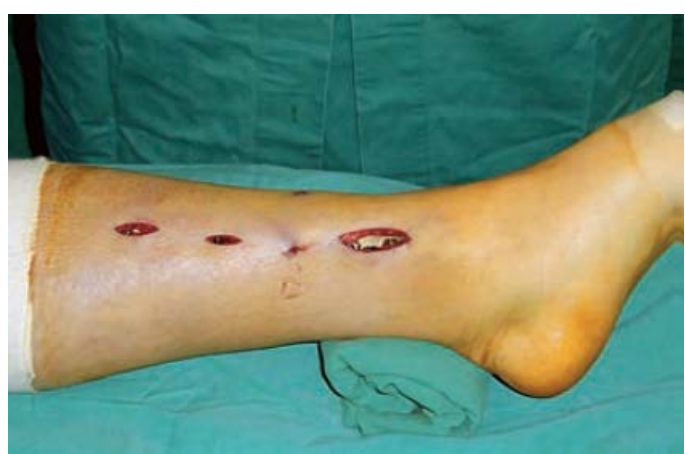

Fig.2: MIPPO technique requires only small incisions.

\section{Postoperative management:}

- Patients with fibular fracture and not fixed were put in posterior slab.

-Immediate postoperative X-rays were obtained: whole leg AP and Lat.

-Neurovascular status was examined. 
-Intravenous broad-spectrum antibiotics were prescribed for two days.

-Low molecular weight heparin was given every 24 hours postoperative to all patients till mobilization as prophylaxis against DVT and pulmonary embolism. -Patients were discharged from the hospital on the third postoperative day on oral broad-spectrum antibiotics for one week, analgesics and antiedematous medications, and instructions for knee and ankle ROM and quadriceps muscle exercise, but not allowed to weight bear.

\section{Follow-up program:}

At 2 weeks: stitches were removed, Weight bearing was restricted to the injured side with crutches held on the other side.

At 6 weeks: the patients were screened for any infection and follow-up AP and Lat whole leg X-rays were done. Range of motion and strengthening of the muscles were assessed. Patients were allowed toetouch weight bearing.

At 12 weeks (3 months): X-rays were done to check for signs of union or fixation failure.

At 24 weeks (6 months): Follow-up X-rays were obtained. If full union occurred, patients were instructed to start full weight bearing. Olerud and Molander scoring system was recorded.

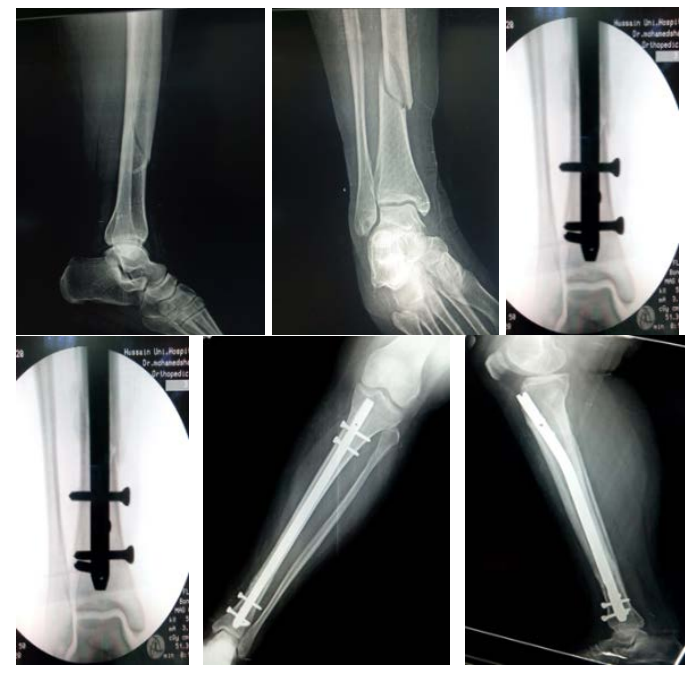

Fig.3: A female patient aged 38 years old had distal tibia fracture after falling to ground that was classified as 43-A1 according to AO classification. Operated using ILN with preoperative, intraoperative radiographs and follow-up after 6 months $\mathrm{X}$-ray showing complete union of the fracture.

\section{Statistical Analysis:}

Our results were evaluated by Independent t-test and Chi-square test. $\mathrm{P}$ value $<0.05$ was considered statistically significant.

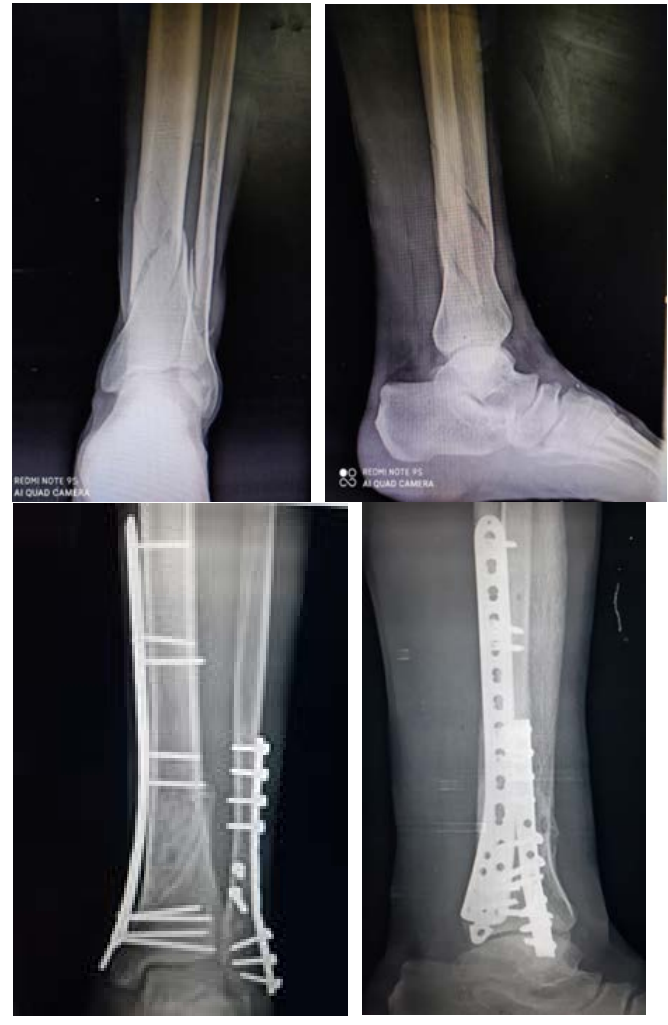

Orthopedic

Fig.4: male patient aged 40 years old had a fracture distal both bone leg after RTA that was classified as 43-A2 according to AO classification. Operated using the MIPO technique with preoperative radiographs and follow-up after 6 months X-ray showing complete union of the fracture.

\section{RESULTS}

\section{Patient Characteristics}

A total of 20 patients were involved in this study. In the ILN group, there were 7 males (70\%) and 3 females (30\%); in the MIPPO group alsothere were 7 males (70\%) and 3 females (30\%). The mean age for the ILN group was 33.10 years \pm 10.90 , with the youngest 20 years old and the oldest 57 years old; while in the MIPPO group the mean age was $36.30 \pm$ 13.43 years, with the youngest 20 years old and the oldest 55 years old. The 20 patients were followedup for at least 6 months and up to 9 months. The mean follow-up period was 7.13 months (Figures 3 and 4).

There was no significant difference between the 2 groups regarding demographic data and characteristics of the studied cases, no significant difference between the 2 groups regarding mode of trauma, fracture side and fibular fracture, no significant difference between the 2 groups regarding AO classification of the fracture, no significant difference between the 2 groups regarding Olerud and Molander score, no significant difference between the 2 groups regarding complications and need for secondary procedure.

There was significant difference between the 2 groups regarding fibular fixation and a significant difference between the 2 groups regarding union. 
Table (1): Demographic data and characteristics of the studied cases

\begin{tabular}{|c|c|c|c|c|c|c|}
\hline & \multirow{2}{*}{\begin{tabular}{|l|} 
Nail group \\
No. $=10$ \\
\end{tabular}} & \multirow{2}{*}{\begin{tabular}{|l|} 
Plate group \\
No. $=10$ \\
\end{tabular}} & \multirow{2}{*}{ Test value } & \multirow{2}{*}{ P-value } & \multirow{2}{*}{ Sig. } \\
\hline & & & & & & \\
\hline Age & $\begin{array}{l}\text { Mean } \pm \text { SD } \\
\text { Range }\end{array}$ & $\begin{array}{l}33.10 \pm 10.90 \\
20-57\end{array}$ & $\begin{array}{l}36.30 \pm 13.43 \\
20-55\end{array}$ & $-0.585 \bullet$ & 0.566 & NS \\
\hline Sex & $\begin{array}{l}\text { Male } \\
\text { Female }\end{array}$ & $\begin{array}{l}7 \text { (70.0\%) } \\
3(30.0 \%)\end{array}$ & $\begin{array}{l}7(70.0 \%) \\
3(30.0 \%)\end{array}$ & $0.000 *$ & 1.000 & NS \\
\hline Occupation & $\begin{array}{l}\text { Light Activity } \\
\text { Moderate } \\
\text { Heavy }\end{array}$ & $\begin{array}{l}1(10.0 \%) \\
2(20.0 \%) \\
7(70.0 \%)\end{array}$ & $\begin{array}{l}0(0.0 \%) \\
6(60.0 \%) \\
4(40.0 \%)\end{array}$ & $3.818^{*}$ & 0.148 & NS \\
\hline HTN & $\begin{array}{l}\text { No } \\
\text { Yes0 }\end{array}$ & $\begin{array}{l}9(90.0 \%) \\
1(10.0 \%)\end{array}$ & $\begin{array}{l}9(90.0 \%) \\
1(10.0 \%)\end{array}$ & $0.000 *$ & 1.000 & NS \\
\hline DM & $\begin{array}{l}\text { No } \\
\text { Yes }\end{array}$ & \begin{tabular}{|l|l}
$10(100.0 \%)$ \\
$0(0.0 \%)$
\end{tabular} & $\begin{array}{l}9(90.0 \%) \\
1(10.0 \%)\end{array}$ & $1.053^{*}$ & 0.305 & NS \\
\hline
\end{tabular}

Table (2): Mode of trauma, fracture side and fibular fracture in the two studied groups

\begin{tabular}{|c|c|c|c|c|c|c|}
\hline & & Nail group & Plate group & ATest value & P-value & Sig \\
\hline & & No. $=10$ & No. $=10$ & Iest value & P-value & Sig. \\
\hline Mode of trauma & $\begin{array}{l}\text { Direct } \\
\text { RTA } \\
\text { FFH } \\
\text { FTG } \\
\end{array}$ & $\begin{array}{l}2(20.0 \%) \\
5(50.0 \%) \\
0(0.0 \%) \\
3(30.0 \%) \\
\end{array}$ & $\begin{array}{l}4(40.0 \%) \\
3(30.0 \%) \\
0(0.0 \%) \\
3(30.0 \%) \\
\end{array}$ & $1.167^{*}$ & 0.558 & NS \\
\hline Fracture side & $\begin{array}{l}\mathrm{Rt} \\
\mathrm{Lt} \\
\end{array}$ & $\begin{array}{l}4(40.0 \%) \\
6(60.0 \%) \\
\end{array}$ & $\begin{array}{l}4(40.0 \%) \\
6(60.0 \%) \\
\end{array}$ & $0.000^{*}$ & 1.000 & NS \\
\hline Fibular fracture & \begin{tabular}{|l|} 
Intact \\
Fractured
\end{tabular} & $\begin{array}{l}1(10.0 \%) \\
9(90.0 \%)\end{array}$ & $\begin{array}{l}1(10.0 \%) \\
9(90.0 \%) \\
\end{array}$ & 0.000 & 1.000 & NS \\
\hline
\end{tabular}

P-value > 0.05: Non significant; P-value < 0.05: Significant; P-value < 0.01: Highly significant *: Chi-square test

Table (3): AO classification of the fracture in the two studied groups

\begin{tabular}{|l|l|l|l|l|l|}
\hline \multirow{2}{*}{ Classification } & Nail group & Plate group & \multirow{2}{*}{ Test value } & P-value & Sig. \\
\cline { 2 - 6 } & No. $=\mathbf{1 0}$ & No. $=\mathbf{1 0}$ & $1(10.0 \%)$ & & \\
\hline $43 \mathrm{~A} 1.1$ & $5(50.0 \%)$ & $3(30.0 \%)$ & & \\
$43 \mathrm{~A} 1.2$ & $2(20.0 \%)$ & $1(10.0 \%)$ & $5.867^{*}$ & 0.319 & NS \\
$43 \mathrm{~A} 1.3$ & $1(10.0 \%)$ & $1(10.0 \%)$ & & \\
$43 \mathrm{~A} 2.1$ & $0(0.0 \%)$ & $2(20.0 \%)$ & & \\
$43 \mathrm{~A} 2.3$ & $2(20.0 \%)$ & $2(20.0 \%)$ & & \\
$43 \mathrm{~A} 3.3$ & $0(0.0 \%)$ & & & \\
\hline
\end{tabular}

P-value > 0.05: Non significant; P-value < 0.05: Significant; P-value < 0.01: Highly significant *: Chi-square test

Table (4): Comparison between nail group and plate group regarding fibular fixation

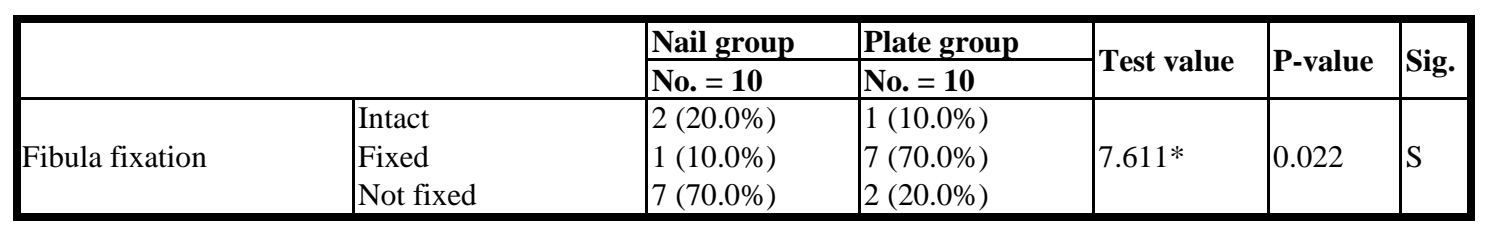

Table (5): Comparison between nail group and plate group regarding time for union

\begin{tabular}{|c|c|c|c|c|c|}
\hline \multirow{2}{*}{ Time for union } & Nail group & Plate group & \multirow{2}{*}{ Test value } & \multirow{2}{*}{ P-value } & \multirow{2}{*}{ Sig. } \\
\hline & No. $=10$ & No. $=10$ & & & \\
\hline Mean \pm SD & $13.10 \pm 1.52$ & $16.78 \pm 4.06$ & \multirow{2}{*}{$-2.673 \bullet$} & \multirow{2}{*}{0.016} & \multirow{2}{*}{$S$} \\
\hline Range & $12-16$ & $12-24$ & & & \\
\hline
\end{tabular}

P-value > 0.05: Non significant; P-value $<0.05$ : Significant; P-value $<0.01$ : Highly significant

$\bullet$ Independent t-test 
Table (6): Comparison between nail group and plate group regarding Olerud and Molander score

\begin{tabular}{|l|l|l|l|l|l|}
\hline \multirow{2}{*}{ Score } & Nail group & Plate group & \multirow{2}{*}{ Test value } & \multirow{2}{*}{ P-value } & \multirow{2}{*}{ Sig. } \\
\cline { 2 - 3 } & No. = 10 & No. = 10 & & \\
\hline Excellent & $8(80.0 \%)$ & $5(50.0 \%)$ & & \\
\hline Good & $2(20.0 \%)$ & $4(40.0 \%)$ & \multirow{2}{*}{$2.359 *$} & \multirow{2}{*}{0.307} \\
\hline Fair & $0(0.0 \%)$ & $0(0.0 \%)$ & & \\
\hline Poor & $0(0.0 \%)$ & $1(10.0 \%)$ & & \\
\hline
\end{tabular}

Table (7): Comparison between nail group and plate group regarding complications.

\begin{tabular}{|c|c|c|c|c|c|}
\hline \multirow{2}{*}{ Complication } & Nail group & Plate group & \multirow{2}{*}{ Test value } & \multirow{2}{*}{ P-value } & \multirow{2}{*}{ Sig. } \\
\hline & No. $=10$ & No. $=10$ & & & \\
\hline Non & $8(80.0 \%)$ & $7(70.0 \%)$ & 0.267 & 0.605 & NS \\
\hline Delayed union & $0(0.0 \%)$ & $1(10.0 \%)$ & 1.053 & 0.304 & NS \\
\hline DVT & $0(0.0 \%)$ & $1(10.0 \%)$ & 1.053 & 0.304 & NS \\
\hline Failure of implant & $0(0.0 \%)$ & $0(0.0 \%)$ & 0.000 & 1.000 & NS \\
\hline \multicolumn{6}{|l|}{ Malunion } \\
\hline No & $8(80.0 \%)$ & $8(80.0 \%)$ & \multirow{5}{*}{$4.000^{*}$} & \multirow{5}{*}{0.261} & \multirow{5}{*}{ NS } \\
\hline Sagittal plane deformity & $0(0.0 \%)$ & $0(0.0 \%)$ & & & \\
\hline Coronal plane deformity & $2(20.0 \%)$ & $0(0.0 \%)$ & & & \\
\hline Rotation & $0(0.0 \%)$ & $1(10.0 \%)$ & & & \\
\hline Nonunion & $0(0.0 \%)$ & $1(10.0 \%)$ & & & \\
\hline \multicolumn{6}{|l|}{ Infection } \\
\hline Non & $10(100.0 \%)$ & $9(90.0 \%)$ & \multirow{3}{*}{$1.053^{*}$} & \multirow{3}{*}{0.305} & \multirow{3}{*}{ NS } \\
\hline Superficial infection & $0(0.0 \%)$ & $0(0.0 \%)$ & & & \\
\hline Deep infection & $0(0.0 \%)$ & $1(10.0 \%)$ & & & \\
\hline \multicolumn{6}{|c|}{ Need for secondary procedure } \\
\hline No & $10(100.0 \%)$ & $9(90.0 \%)$ & \multirow{4}{*}{$1.053^{*}$} & \multirow{4}{*}{0.305} & \multirow{4}{*}{ NS } \\
\hline Dynamization & $0(0.0 \%)$ & $0(0.0 \%)$ & & & \\
\hline Debridement & $0(0.0 \%)$ & $0(0.0 \%)$ & & & \\
\hline Revision & $0(0.0 \%)$ & $1(10.0 \%)$ & & & \\
\hline
\end{tabular}

P-value > 0.05: Non significant; P-value $<0.05$ : Significant; P-value $<0.01$ : Highly significant *: Chi-square test

Table (8): Relation between classification in nail, Plate groups and Olerud and Molander score

\begin{tabular}{|c|c|c|c|c|c|c|}
\hline \multirow{2}{*}{ Score } & 43A1 & 43A2 & 43A3 & \multirow{2}{*}{ Test value } & \multirow{2}{*}{ P-value } & \multirow{2}{*}{ Sig. } \\
\hline & No. $=8$ & No. $=0$ & No. $=2$ & & & \\
\hline \multicolumn{7}{|c|}{ Classification in Nail group } \\
\hline Excellent & $7(87.5 \%)$ & $0(0.0 \%)$ & $1(50.0 \%)$ & \multirow{4}{*}{$1.406^{*}$} & \multirow{4}{*}{0.236} & \multirow{4}{*}{ NS } \\
\hline Good & $1(12.5 \%)$ & $0(0.0 \%)$ & $1(50.0 \%)$ & & & \\
\hline Fair & $0(0.0 \%)$ & $0(0.0 \%)$ & $0(0.0 \%)$ & & & \\
\hline Poor & $0(0.0 \%)$ & $0(0.0 \%)$ & $0(0.0 \%)$ & & & \\
\hline \multicolumn{7}{|c|}{ Classification in Plate group } \\
\hline Excellent & $2(40.0 \%)$ & $1(100.0 \%)$ & $2(50.0 \%)$ & \multirow{4}{*}{$2.100 *$} & \multirow{4}{*}{0.717} & \multirow{4}{*}{ NS } \\
\hline Good & $2(40.0 \%)$ & $0(0.0 \%)$ & $2(50.0 \%)$ & & & \\
\hline Fair & $0(0.0 \%)$ & $0(0.0 \%)$ & $0(0.0 \%)$ & & & \\
\hline Poor & $1(20.0 \%)$ & $0(0.0 \%)$ & $0(0.0 \%)$ & & & \\
\hline
\end{tabular}

P-value > 0.05: Non significant; P-value $<0.05$ : Significant; P-value $<0.01$ : Highly significant *: Chi-square test 


\section{DISCUSSION}

Tibial fractures are seen often, and successful results may be achieved with various surgical techniques. Distal tibial fractures are much more problematic because of the surrounding soft tissues being thinner than the proximal tissues and the poor vascularization. ${ }^{7}$ Although distal tibial locked plate with MIPPO technique and ILN have proven to be effective widely accepted treatment options for distal tibial fractures, limited comparative literature exists to optimize treatment decision. ${ }^{8}$

A total of 20 patients were included in the study (males 14, females 6) with mean age of 33.10 years and standard deviation 10.90 of group A and mean age of 36.30 and standard deviation 13.43 of group B. 10 patients in group A:ILN, and 10 patients in group B: distal tibial locked plate with MIPPO technique. Epidemiological (Age, sex, Occupation and comorbidities) ,preoperative (MOT, AO classification, associated fibular fracture) and operative time showing no statistically significant in both groups, our assessment measurements including superficial infection, deep infection, union (united, delayed union, non-union), Alignment, need for secondary operations (dynamization, debridement, revision) and Olerud and Molander score after 6 months.

Regarding to time of surgery, in group A mean operative time was 116 min. with standard deviation16.47. Group B mean operative time was 127 with standard deviation 18.89. $\mathrm{P}$ value.182 which is not significant in this study. Guo et al. ${ }^{9}$ and Li Y, Jiang et al. ${ }^{8}$ showed significant decrease in operative time in ILN group. Time of surgery depends on many factors: presence of fibular fracture, difficultiesin reduction, presence of good assistance and the expert of surgeon.

In our study, no patients in group A developed infection.While in group B,1 patient develop deep infection which was resistance and ended with nonunion and need revision. Delayed debridement time due to patient was uncooperative was most probably the cause of resistance infection.Li Y, Jiang et al. ${ }^{8}$ showed significant increase in superficial infection with plate group, while Mauffrey et al. ${ }^{10}$ showed the opposite. The other studies showed no significant in both groups. Infection (deep and superficial) showed best outcome if detected early and aggressive intervention. So, patient follow up is very important to early detection ofinfection. Mode of trauma,good handling to soft tissues and skin coverage and general condition of the patient were also important factors in development of infection.

Time to union in our study showed statistically significant decreased in ILN. In ILN group time to union was 13.10 weeks with SD 1.52, while in MIPPO 16.78 with SD 4.06.P value is.0.016This is the main significant result in our study. Other studies showed no significant difference in both groups. ILNs are weight shearing devices while Plates are weight bearing. This may allow to decide partial weight bearing earlier in ILN group which create micromotions in fracture site and induce healing.
In MIPPO group one patient showed rotational deformity (25-degree external rotation), and one patient show delayed union, In ILN 2patients showed coronal plane malalignment. Mauffrey et al. ${ }^{10}$ showed significant non-union rate in plate group, while other studies showed no significant differences in both groups in union rate. Vallier et al. ${ }^{7}$ showed significant mal-alignment reduction in ILN group. Theflare of junction between diaphysis and metaphysis increase the challenge of accepted reduction specially in ILN.

Mauffrey et al. ${ }^{10}$ showed significant need for secondary surgeries in plate group,Debridement and removal of plate after short time of union due to skin irritation were the main secondary operations in plate group, while dynamization (removal of dynamic screw) is the majority in ILN group. Other studies showed no significant differences in need for secondary operation.

In our study, 5 patients in MIPPO group get excellent in Olerud and Molander score ${ }^{11}$ and 4 get good while 1 was poor. Patient with poor score who develop infection nonunion. In ILN group, 8 patientsget excellent, 2 patients were good. $\mathrm{P}$ value regarding to Olerud and Molander score ${ }^{11}$ in both groups was 0.307 which is statistically insignificant. Each study used different outcome clinical scores at the end of follow up, no significant differences in clinical outcome comparing both groups.

\section{CONCLUSION}

Both techniques can provide effective treatment and fixation for closed extraarticular fractures. ILN showed lower infection rate and faster time to healing but with more mal-alignment reduction. While in MIPPO technique less mal-alignment reduction could be achieved but with more infection problems and slower rate of union. Good handling to soft tissues is an important factor to rapid healing of the fracture and to avoid complications. Good preoperative planning for each patient to achieve good reduction with minimal soft tissue injury was an important as it reduce time of operation and the need for secondary surgeries.

Further studies with longer period of follow up and larger number of patients is needed to help orthopedic surgeons to proper choice of technique and implant.

\section{REFERENCES}

1. Ronga $\mathrm{M}$, Longo UG, and Maffulli $\mathrm{N}$. Minimally invasive locked plating of distal tibia fractures is safe and effective. Clinical Orthopaedics and Related Research. 2010; 468, 975-982.

2. Achten, and Juul. UK Fixation of Distal Tibia Fractures (UK FixDT): protocol for a randomised controlled trial of 'locking'plate fixation versus intramedullary nail fixation in 
the treatment of adult patients with a displaced fracture of the distal tibia. BMJ open. 2015; 5.9.

3. Heckman and James D. Rockwood and Green's fractures in adults. Lippincott Williams \& Wilkins. 2014; Eighth Edition 1-2.

4. Shrestha D, Acharya BM, and Shrestha PM. Minimally invasive plate osteosynthesis with locking compression plate for distal diametaphyseal tibia fracture. Kathmandu University Medical Journal. 2011; 9.2: 62-68

5. Lai TC, and Fleming JJ. Minimally invasive plate osteosynthesis for distal tibia fractures. Clinics in podiatric medicine and surgery. 2018; 35(2):223-32.

6. Azar, Frederick M, CANALE S Terry, et al. Campbell's operative orthopaedics e-book. Elsevier Health Sciences. 2016.

7. Vallier HA, Cureton BA, and Patterson BM. Randomized, Prospective Comparison of Plate versus Intramedullary Nail Fixation for Distal Tibia Shaft Fractures. J Orthop Trauma. 2011; 44109, 736-741.

8. Li Y. Treatment of distal tibial shaft fractures by three different surgical methods: A randomized, prospective study. Int. Orthop. 2014; 38, 12611267.

9. Guo JJ. A prospective, randomised trial comparing closed intramedullary nailing with percutaneous plating in the treatment of distal metaphyseal fractures of the tibia. The Journal of bone and joint surgery. British volume. 2010; 92.7: 984-988.

10. Mauffrey C. A randomised pilot trial of "locking plate" fixation versus intramedullary nailing for extra-articular fractures of the distal tibia. The Journal of Bone and Joint Surgery. British volume. 2012; 94.5: 704-708.

11. Nilsson, abd Gertrud. Outcome and quality of life after surgically treated ankle fractures in patients 65 years or older. BMC musculoskeletal disorders. 2007; 8.1: 1-9. 